\title{
PREPARATION OF AMMONIUM POLYPHOSPHATE AND ITS APPLICATION TO FLAME RETARDANT
}

\author{
Makoto WATANABE*, Makoto SAKURAI, Mioko MAEDA \\ (*Corresponding author:watanabe@isc.chubu.ac.jp)
}

Department of Applied Chemistry, College of Engineering, Chubu University, Matsumoto-cho, Kasugai, Aichi 487-8501, JAPAN

Key words: ammonium polyphosphate, flame retardant, condensed phosphate

Abstract: Ammonium polyphosphate forms II, V, and VI have been prepared by new preparation processes using ammonium orthophosphate, urea and/or phosphorus pentaoxide as starting materials. The preparation processes are very useful for a large scale preparation in a factory. These crystal phases of APP showed flame retardant effect to organic polymer materials. The order of flame retardation effect among the phases was $\mathrm{V}>\mathrm{II}>\mathrm{VI} \geqq \mathrm{I}$.

(Received January 9, 2009; Accepted February 24, 2009)

\section{INTRODUCTION}

Many kinds of organic polymer materials have been used in various fields of construction, home furnishing, electric and electronic materials, vehicles, and other industrial applications, because of their excellent characteristics. One of the weak points of them is flammability. Growing use of organic polymer materials is requiring retardation of flammability. There are several ways to give retardation of flammability to organic polymer materials. One of the good ways is to add flame retardants to polymer materials. There are many kinds of flame retardants. P-N compounds are useful flame retardants to polymer materials. ${ }^{1,2,3,4,5)}$ Among many kinds of P-N compounds, ammonium polyphosphate (APP) is a useful compound for flame retardation of organic polymer materials when it is added to organic materials and the compound is environmentally friendly and a low cost substance.
APP has six crystal forms ${ }^{6,7)}$ and form I has been prepared very easily, but other crystal forms are difficult to produce and sophisticated preparation processes are required to produce them. In this study, preparation processes of APP forms II, V, VI and flame retardation effect of the APP phases will be described.

\section{EXPERIMENTAL PROCEDURES}

\subsection{Preparation of APP form I}

APP form I was prepared by heating an equimolar mixture of ammonium dihydrogenorthophosphate and urea at 250 to $300{ }^{\circ} \mathrm{C}$.

\subsection{Preparation of APP form II}

Preparation of form II APP was carried out by heating form I APP under alternate gas flow of wet ammonia and dry air at 270 to $290{ }^{\circ} \mathrm{C}$, and also by heating a mixture of ammonium orthophosphate and 
urea at 250 to $305{ }^{\circ} \mathrm{C}$ under wet ammonia. The wet ammonia was prepared by passing air through aqueous ammonia having various concentrations at flow rate of $40 \mathrm{dm}^{3} / \mathrm{h}$. Aqueous ammonia was changed every $20 \mathrm{~min}$ to prevent lowering of concentration of aqueous ammonia.

\subsection{Preparation of APP form V}

Preparation of form V APP was examined by heating the same mixture as that of the preparation of form II APP at 320 to $350{ }^{\circ} \mathrm{C}$ under wet ammonia which was prepared by passing purchased ammonia gas through $29 \%$ of aqueous ammonia.

\subsection{Preparation of APP form VI}

Form VI APP was tried to prepare by heating a mixture of phosphorus pentaoxide and urea at 250 to $290{ }^{\circ} \mathrm{C}$ under air and wet ammonia which was obtained by passing air through aqueous ammonia having various concentrations.

\subsection{Analytical methods}

An X-ray diffraction analysis of a powder sample was employed to examine the production of APP forms I, II, V, and VI. The content (\%) of APP phase in a product was calculated automatically by the calculation program installed in a computer that is attached to the XRD instrument. The standard XRD diagrams of APP forms I to VI are shown in Fig. 1. Scanning electron microscopic (SEM) observation of an APP sample was made to check particle size and shape of the sample. Particle size distribution was measured by a centrifugal sedimentation technique, using isobutyl alcohol as a sedimentation medium. Determination of phosphorus and nitrogen was achieved by the Molybdenum Blue method and Kjeldahl technique, respectively. Flame retardation effect of APP was tested with a sample which was prepared by adding APP to organic polymer materials by using a mixing roller. The oxygen-index technique was employed to study flame retardation effect of APP.

\section{RESULTS AND DISCUSSION}

\subsection{Preparation of form II APP}

3.1.1. Transformation of APP form I to II ${ }^{8,9,10)}$

Shen and his coworkers showed that the transformation of APP form I to II was accelerated by the presence of an amorphous phase and the amorphous phase was produced by removing a small amount of ammonia of APP or by introducing a small amount of water vapor into the reaction system. ${ }^{6}$ ) Accordingly, the phase transition of form I to II is thought to be progressed by the following process:

APP form I $\rightarrow$ Amorphous phase $\rightarrow$ APP form II

(Stage 1)

(Stage 2)

Stage 1 is accelerated by removing a small amount of ammonia or by introducing a small amount of water vapor as they wrote. Accordingly, amorphous APP produced by the process would be ammonium-deficient APP. When the amorphous APP is crystallized to APP form II, ammonia would be required to produce a well crystallized form II APP. From the basic consideration, the preparation of form II APP according to the phase transition of APP form I was examined under several atmospheric conditions. Heating temperature is also very important factor for the phase transition.

The results of phase transition of APP form I to II in dry air, dry ammonia, and wet ammonia are listed in Table 1. From the results, it was impossible to achieve $100 \%$ of phase transition of APP form I to II. Among the reaction conditions, dry air and wet ammonia gave a fairly good result. 


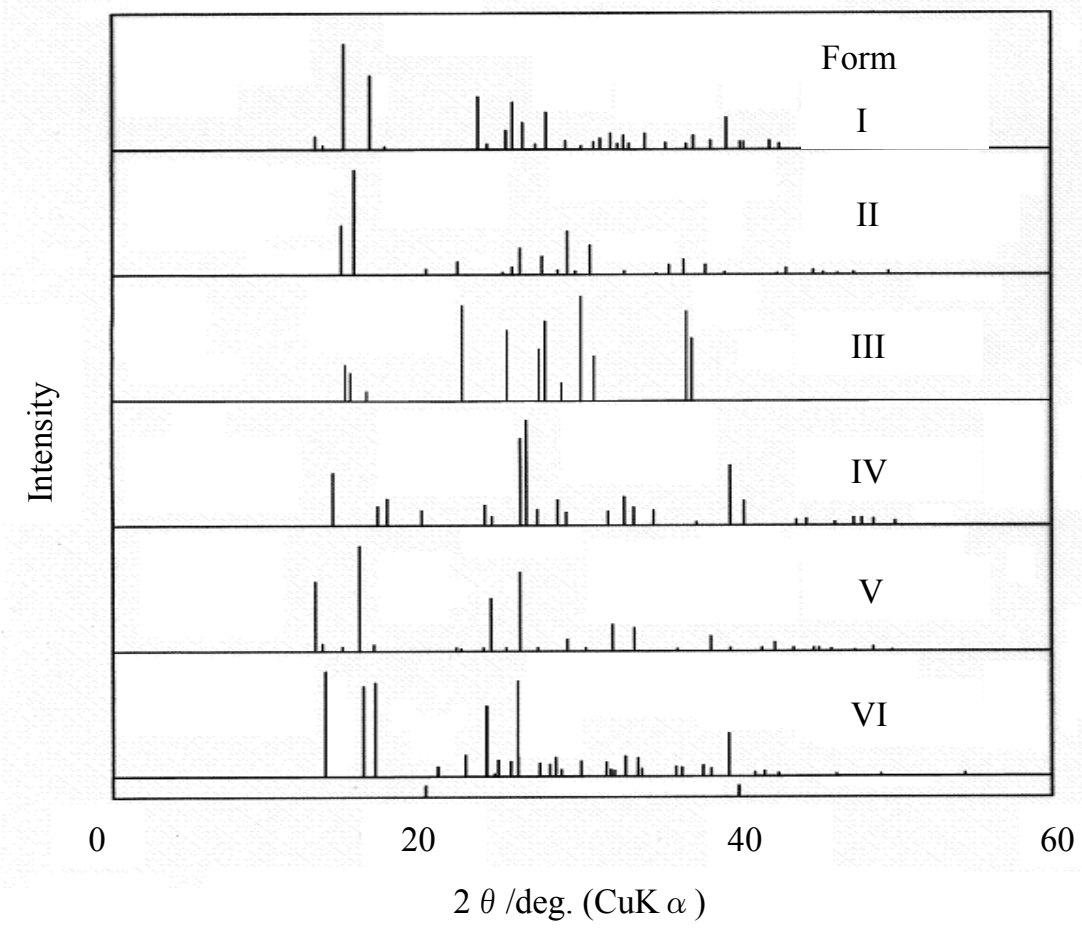

FIGURE 1 XRD diagrams of APP forms I to VI

TABLE 1 Phase transition of APP form I to II

\begin{tabular}{ccc}
\hline \multirow{2}{*}{ Atmosphere } & Reaction temp. $\left({ }^{\circ} \mathrm{C}\right)$ & Content (\%) of APP form II \\
\hline \multirow{2}{*}{ Dry air } & 250 & 62 \\
& 260 & 65 \\
\hline \multirow{3}{*}{ Dry ammonia } & 250 & 11 \\
& 260 & 11 \\
& 270 & 11 \\
& 280 & 12 \\
& 290 & 12 \\
& 300 & 15 \\
\hline \multirow{3}{*}{ Wet ammonia } & 250 & 13 \\
& 260 & 16 \\
& 270 & 18 \\
& 280 & 32 \\
& 290 & 50 \\
& 300 & 86 \\
\hline
\end{tabular}


Therefore, alternate gas flow of dry air and wet ammonia was examined and the condition of alternate-exchanging gas flow of wet ammonia and dry air is indicated in Table 2. XRD diagrams of the products which were obtained according to the reaction condition in Table 2 and at $270{ }^{\circ} \mathrm{C}$ using $3 \%$ of aqueous ammonia are indicated in Fig. 2. The phase transition of APP form I to II under the reaction conditions listed in Table 2 was examined and the results shown in Table 3 were obtained.

The results in Table 3 show that the $100 \%$ of phase transition of APP form I to II was achieved under alternate gas-flow condition of No. 2 to 4 , reaction temperature of 270 to $290{ }^{\circ} \mathrm{C}$ and concentration of aqueous ammonia of 3 to $5 \%$. Concentration of aqueous ammonia less than $3 \%$ did

TABLE 2 Condition of alternate gas flow

\begin{tabular}{cccc}
\hline & $\begin{array}{c}\text { Exchanging condition } \\
\text { of flow gas (min) }\end{array}$ & $\begin{array}{c}\text { Total reaction } \\
\text { time (min) }\end{array}$ \\
\hline & Wet NH $_{3}$ & Dry air & \\
\hline 1 & 3 & 7 & 33 \\
3 & 6 & 14 & 66 \\
4 & 9 & 21 & 99 \\
\hline
\end{tabular}

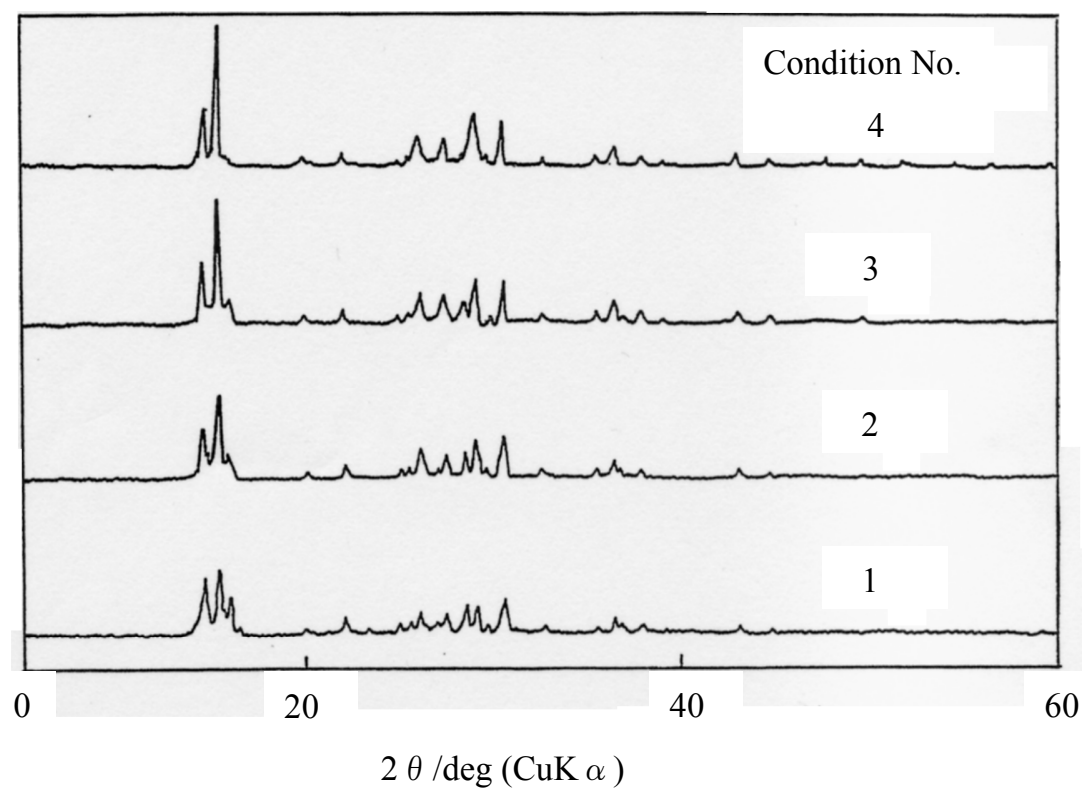

FIGURE 2 XRD diagrams of the products of the phase transition of APP form I to II at $270{ }^{\circ} \mathrm{C}$ using $3 \%$ aqueous ammonia 


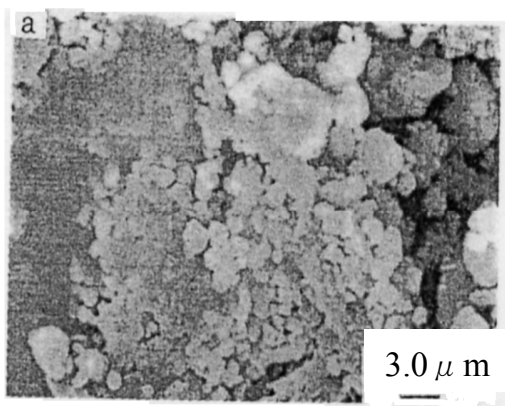

APP I

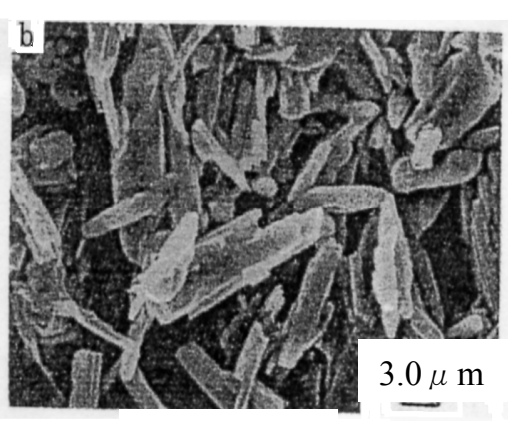

APP II

FIGURE 3 SEM photographs of APP forms I and II

TABLE 3 Phase transition of APP form I to II under various reaction conditions

\begin{tabular}{|c|c|c|c|c|c|}
\hline \multirow{3}{*}{$\begin{array}{l}\text { Concentration of } \\
\text { aqueous ammonia (\%) }\end{array}$} & \multirow{3}{*}{$\begin{array}{l}\text { Reaction } \\
\text { temp. }\left({ }^{\circ} \mathrm{C}\right)\end{array}$} & \multicolumn{4}{|c|}{ Content (\%) of APP form II } \\
\hline & & \multicolumn{4}{|c|}{ Condition No. } \\
\hline & & 1 & 2 & 3 & 4 \\
\hline \multirow{6}{*}{8} & 270 & 71 & 93 & 94 & 88 \\
\hline & 280 & 59 & 77 & 87 & 94 \\
\hline & 290 & 64 & 91 & 96 & 98 \\
\hline & 300 & 54 & 86 & 95 & melt \\
\hline & 310 & 80 & 98 & 89 & melt \\
\hline & 270 & 28 & 65 & 84 & 66 \\
\hline \multirow{4}{*}{5} & 280 & 71 & 71 & 96 & 89 \\
\hline & 290 & 78 & 90 & 100 & 95 \\
\hline & 300 & 71 & 92 & 97 & melt \\
\hline & 310 & 89 & 98 & 88 & melt \\
\hline \multirow{5}{*}{3} & 270 & 77 & 83 & 89 & 100 \\
\hline & 280 & 92 & 100 & 100 & 100 \\
\hline & 290 & 80 & 100 & 100 & melt \\
\hline & 300 & 74 & melt & melt & melt \\
\hline & 310 & 86 & melt & melt & melt \\
\hline
\end{tabular}


not give a good phase transition of APP form I to II at any reaction temperature. SEM photographs of APP forms I and II are shown in Fig. 3. APP form I showed a small particle size and form II exhibited a large crystal shape. The all products showed $\mathrm{P} / \mathrm{N}$ ratio of 0.93 to 1.06 and the ratios are almost equal to the standard ratio (1.0) of APP.

3.1.2. Preparation of APP form II from the system of ammonium orthophosphate-urea $^{9,10)}$

Preparation of form II APP has usually been done by using phosphorus pentaoxide in factory scale, but phosphorus pentaoxide is very reactive with moisture in the air and, therefore, treatment in large scale is not easy in a production field, and the substance is also harmful to human body. Accordingly, the direct preparation of form II APP from an easy reaction system to human body and also easy to a large scale production in a factory was examined by using the system of ammonium orthophosphate-urea. The reaction system is environmentally friendly. The direct preparation of form II APP from the system was successfully achieved in this experiment. A part of the results is indicated in Table 4.

TABLE 4 Content of form II APP in the thermal products of the reaction system of ammonium orthophosphate-urea

\begin{tabular}{|c|c|c|c|c|c|c|}
\hline $\begin{array}{c}\text { Mixing molar ratio } \\
{\left[\left(\mathrm{NH}_{4}\right)_{2} \mathrm{HPO}_{4}: \mathrm{CO}\left(\mathrm{NH}_{2}\right)_{2}\right]}\end{array}$ & \multicolumn{2}{|c|}{$1: 3$} & \multicolumn{2}{|c|}{$1: 2$} & \multicolumn{2}{|c|}{$1: 1$} \\
\hline Reaction time (min) & 30 & 60 & 30 & 60 & 30 & 60 \\
\hline \multicolumn{7}{|l|}{ Reaction temp. $\left({ }^{\circ} \mathrm{C}\right)$} \\
\hline 270 & $\triangle$ & $\bigcirc$ & $\triangle$ & $\triangle$ & $x$ & $\triangle$ \\
\hline 280 & (0) & (0) & $\triangle$ & (a) & $x$ & $x$ \\
\hline 290 & (0) & (0) & (0) & (0) & $\triangle$ & $\bigcirc$ \\
\hline 300 & (2) & (0) & (0) & (0) & $\triangle$ & (a) \\
\hline 305 & (0) & (0) & (0) & (2) & $\triangle$ & (a) \\
\hline
\end{tabular}

APP content: $\times ; 0 \sim 50 \%, \triangle ; 50 \sim 70 \%, \bigcirc ; 70 \sim 90 \%$, ○); higher than $90 \%$.

There are three kinds of ammonium orthophosphates of triammonium orthophosphate, diammonium hydrogenorthophosphate and ammonium dihydrogenorthophosphate. Among them, diammonium hydrogenorthophosphate gave the best result. Mixing molar ratio of diammonium hydrogenorthophosphate and urea, reaction temperature, atmospheric condition were examined to find a good preparation result of APP form II. As for atmospheric condition, wet ammonia which was obtained by passing air through 3 to $5 \%$ of aqueous ammonia gave the best result. According to the results in Table 4, reaction temperature of 280 to 305 ${ }^{\circ} \mathrm{C}$ and mixing molar ratio of $1: 3$ to $1: 2$ seemed to be 
the best reaction condition to prepare form II APP from the reaction system. Under the reaction condition, form II APP can be prepared in 30 to 60 $\min$.

$\mathrm{P} / \mathrm{N}$ molar ratios of the products were 0.97 to 1.04 and the values were close to the standard $\mathrm{P} / \mathrm{N}$ ratio (1.0) of APP.

\subsection{Preparation of form V APP ${ }^{11,12,13)}$}

Direct preparation of form V APP from the system of ammonium orthophosphate and urea was examined. Among the three ammonium orthophosphates, diammonium hydrogenorthophosphate gave the best result. Reaction conditions of mixing molar ratio of the ammonium orthophosphate and urea, atmosphere, heating temperature, and heating time were tested to obtain the best reaction condition of the preparation of form V APP. The results are given in Table 5. Particle size and shape of APP form $\mathrm{V}$ were almost the same as those of APP form I. As it can be seen from the results in Table 5, mixing molar ratio of $1: 4$ to $1: 5$, reaction temperature of 340 to $350{ }^{\circ} \mathrm{C}$, and reaction time of 105 to $120 \mathrm{~min}$ gave an excellent result to prepare APP form $\mathrm{V}$ from

TABLE 5 Content of form V APP in the product

\begin{tabular}{|c|c|c|c|c|c|c|}
\hline \multicolumn{7}{|l|}{ Mixing molar ratio } \\
\hline$\left[\left(\mathrm{NH}_{4}\right)_{2} \mathrm{PO}_{4}: \mathrm{CO}\left(\mathrm{NH}_{2}\right)_{2}\right]$ & \multicolumn{2}{|c|}{$1: 3$} & \multicolumn{2}{|c|}{$1: 4$} & \multicolumn{2}{|c|}{$1: 5$} \\
\hline Reaction temp. $\left({ }^{\circ} \mathrm{C}\right)$ & 340 & 350 & 340 & 350 & 340 & 350 \\
\hline \multicolumn{7}{|l|}{ Reaction time (min) } \\
\hline 30 & $\times$ & $\triangle$ & $\times$ & $\triangle$ & $\times$ & $\bigcirc$ \\
\hline 60 & $x$ & $\bigcirc$ & $\triangle$ & $\bigcirc$ & $\bigcirc$ & (0) \\
\hline 75 & $x$ & $\bigcirc$ & $\bigcirc$ & $\bigcirc$ & $\bigcirc$ & ()) \\
\hline 90 & $\triangle$ & $\bigcirc$ & $\bigcirc$ & (0) & $\bigcirc$ & (0) \\
\hline 105 & $\triangle$ & $\bigcirc$ & (2) & (0) & (0) & (0) \\
\hline 120 & $\triangle$ & $\bigcirc$ & (0) & (0) & (0) & (0) \\
\hline
\end{tabular}

The same marks as those in Table 4 are used.

the reaction system of $\left(\mathrm{NH}_{4}\right)_{2} \mathrm{HPO}_{4}-\mathrm{CO}\left(\mathrm{NH}_{2}\right)_{2}$. Atmospheric condition under wet ammonia which was prepared by passing ammonia gas through $29 \%$ of aqueous ammonia gave the best result.

$\mathrm{P} / \mathrm{N}$ ratios of the products having an APP form- $\mathrm{V}$ content higher than $90 \%$ were 0.96 to 1.03 and the ratios were very close to the standard $\mathrm{P} / \mathrm{N}$ molar ratio (1.0) of APP.

\subsection{Preparation of APP form VI}

Direct preparation of form VI APP was tried with the system of $\mathrm{P}_{2} \mathrm{O}_{5}-\mathrm{CO}\left(\mathrm{NH}_{2}\right)_{2}$. Reaction conditions of mixing molar ratio of phosphorus pentaoxide to urea, reaction temperature, and 
atmospheric condition were studied and the results are listed in Table 6. Particle size and shape of form VI APP were almost the same as those of APP form I. According to the results in Table 6, preferable reaction condition to prepare form VI APP from the system seems to be the molar ratio of 1.0 to 1.5 , reaction temperature of $250{ }^{\circ} \mathrm{C}$, atmosphere under wet ammonia that is prepared by passing air through
$29 \%$ of aqueous ammonia, and reaction time of 60 min. In the air, mixing molar ration of $1: 3.0$ and reaction temperature of 270 to $290{ }^{\circ} \mathrm{C}$ gave an excellent result.

$\mathrm{P} / \mathrm{N}$ molar ratios of the products having an APP form-VI content higher than $90 \%$ were 0.94 to 0.99 and were very close to the standard ratio (1.0) of APP.

TABLE 6 Content of form VI APP in thermal product

\begin{tabular}{|c|c|c|c|c|c|c|}
\hline Reaction temp. $\left(^{\circ}\right.$ & & 210 & 230 & 250 & 270 & 290 \\
\hline $\begin{array}{c}\text { Conc. (\%) of } \\
\text { aqueous ammonia }\end{array}$ & $\begin{array}{l}\text { Mixing molar ratio } \\
{\left[\mathrm{P}_{2} \mathrm{O}_{5}: \mathrm{CO}\left(\mathrm{NH}_{2}\right)_{2}\right]}\end{array}$ & & & & & \\
\hline \multirow{4}{*}{10} & $-1: 0.5$ & melt & melt & melt & melt & melt \\
\hline & $1: 1.0$ & $\triangle$ & $\triangle$ & melt & melt & melt \\
\hline & $1: 1.5$ & $\triangle$ & $\triangle$ & $\triangle$ & $\triangle$ & $\triangle$ \\
\hline & $1: 0.5$ & $\triangle$ & $\triangle$ & melt & melt & melt \\
\hline \multirow[t]{2}{*}{20} & $1: 1.0$ & $\triangle$ & $\triangle$ & $\bigcirc$ & melt & melt \\
\hline & $1: 1.5$ & $x$ & $x$ & (0) & $\triangle$ & $\triangle$ \\
\hline \multirow{3}{*}{29} & $1: 0.5$ & $\triangle$ & $\triangle$ & melt & melt & melt \\
\hline & $1: 1.0$ & $\triangle$ & $\triangle$ & $\bigcirc$ & $\triangle$ & melt \\
\hline & $1: 1.5$ & $x$ & $x$ & (0) & $\triangle$ & $\triangle$ \\
\hline In the air & $1: 3.0$ & $\triangle$ & $\triangle$ & $\bigcirc$ & ()) & ()) \\
\hline
\end{tabular}

The same marks as those in Table 4 are used.

\section{FLAME RETARDATION EFFECT OF APP}

Oxygen indices of organic polymer materials of polyethylene (PE) and polypropylene (PP) containing APP are shown in Table 7. From the results in Table 7, all kinds of APP having forms I, II, $\mathrm{V}$, and VI are effective to the frame retardation on organic polymer materials. The flame retardation effect of APP to organic polymer materials seemed to be dependent on the sort of organic polymer materials and the flame retardation effect of APP was larger to PP than PE. The order of the effectiveness looks like $\mathrm{V}>\mathrm{II}>\mathrm{VI} \geqq \mathrm{I}$. It is very important factor to have a high dispersibility for flame retardants to obtain a high retardation effect. Dispersibility of frame retardants is very dependent on particle size of them. 
Average particle size of APP used in this experiment was $3.6 \mu \mathrm{m}$ of APP-I, $12.6 \mu \mathrm{m}$ of APP-II, $3.0 \mu \mathrm{m}$ of APP-V, and $3.4 \mu \mathrm{m}$ of APP-VI. APP phases II and $\mathrm{V}$ have a higher thermal stability than APP phases I and VI. Accordingly, APP phases II and V show a higher flame retardation effect than APP phases I and VI, because APP phases I and VI decompose at a temperature lower than thermal decomposition temperature of PE and PP. The flame retardation effect of APP phase V is larger than II, because the particle size of APP phase $\mathrm{V}$ is smaller than that of APP phase II and therefore, APP phase V has a higher dispersibility than phase II.

TABLE 7 Oxygen indices of organic polymer materials containing APP

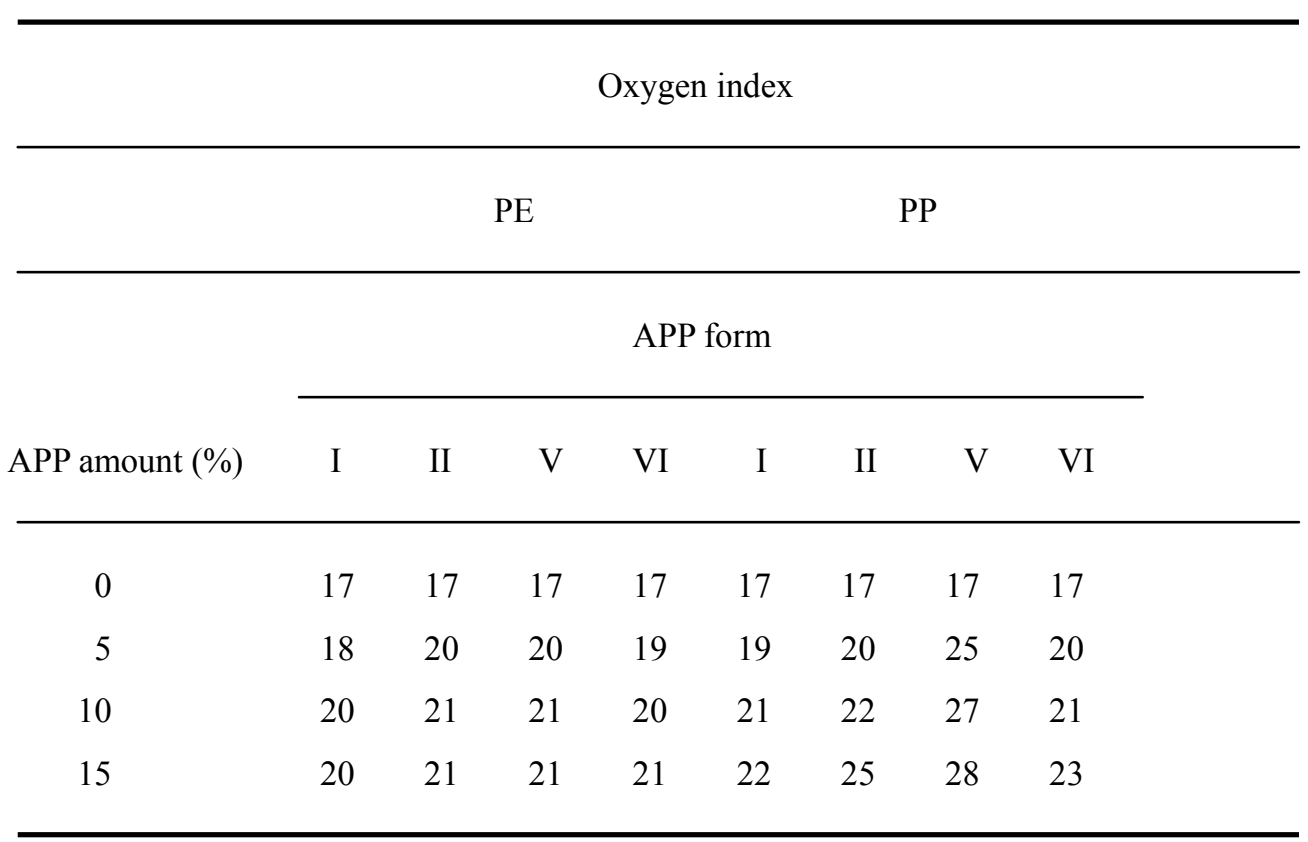

\section{REFERENCES}

1) A. D. F. Toy, E. N. Walsh, Phosphorus Chemistry in Everyday Living, Am. Chem. Soc., Washington, DC (1987), pp.103.

2) E. N. Walsh, E. J. Griffith, R. W. Parry, L. D. Quin, Phosphorus Chemistry, Amer. Chem. Soc., Washigton, DC (1992), pp218.

3) A. F. Grand, C. A. Wilkie, Fire Retardancy of Plymeric Materials, Marcel Dekker, Inc. New York (2000), pp. 147.

4) M. Watanabe, Shikizai, 73, 198 (2000).

5) M. Watanabe, Chem. Eng., 9, 32 (2004).

6) C. Y. Shen, N. F. Stalheber, D. R. Dyroff, J. Am.
Chem. Soc., 91, 62 (1969).

7) K. R. Waerstand, G. H. McClellan, J. Agric. Food Chem., 24, 412 (1976).

8) M. Watanabe, Y. Yamaguchi, M. Sakurai, H. Suzuki, M. Maeda, Inorg. Mater., 6, 48 (1999).

9) M. Watanabe, M. Sakurai, Y. Yamaguchi, M. Watanabe, Phos. Sulf. and Silicon, 144-146.(1999).

10) M. Watanabe, M. Watanabe, M. Sakurai, H. Suzuki, Bull. Chem Soc. Jpn., 73, 115 (2000).

11) H. Suzuki, M. Sakurai, M. Watanabe, J. Soc. Inorg. Mater. Jpn., 177, 359 (2002).

12) M. Watanabe, S. Kawasaki, M. Sakurai, Phos. Sulf. and Silicon, 177, 2243 (2002). 
13) M. Watanabe, H. Suzuki, H. Kawasaki, M. Maeda, M. Sakurai, Phos. Res. Bull., 14, 105 (2003). 